\title{
Relationships of Left Ventricular Systolic Time Intervals with Hemodynamic Variables in Intact and Failing Hearts
}

\author{
Tsuneaki Sugimoto, M.D., * Tohru Inasaka, M.D., * Lotfy L. \\ Basta, M.D., ** and Jugoro Takeuchi, M.D.*
}

\section{SUMMARY}

Deviation of systolic time intervals (STI) from the regression lines obtained from 122 normal subjects was studied in 22 healthy adults (Group 1), 18 N.Y. functional class I cardiac patients (Group II) with ischemic (IHD) or primary myocardial disease (PMD), and 15 similar patients (pts) but N.Y. functional class II with prior heart failure (Group III).

$\mathrm{STI}_{\mathrm{C}}$ (corrected for heart rate) were normal in Groups I and II. Supine exercise caused shortening of pre-ejection period $\mathrm{PEP}_{\mathrm{C}}$ and prolongation of left ventricular ejection time $E T_{C}$ in both groups. Group III pts had a significantly longer PEP $_{C}$ and shorter ET $T_{C}$ at rest. Supine exercise caused further prolongation of $\mathrm{PEP}_{\mathrm{C}}$ and a slight prolongation of $\mathrm{ET}_{\mathrm{C}}$ in this group.

In 8 mongrel dogs, the effect of controlled changes of hemodynamic variables on STI was studied with intact hearts and repeated after myocardial impairment has been induced by pentobarbital. Doubling of venous return while the heart was intact produced changes in STI similar to the effects of supine exercise in Groups I and II human subjects. With myocardial impairment, comparable increase in venous return had an effect on STI similar to the effect of supine exercise in Group III patients. Controlled increase in each of heart rate or blood pressure, with other hemodynamic variables kept constant, produced changes in STI different from the effect of supine exercise on human subjects.

The study suggests that the value of supine exercise induced changes in STI in reflecting left ventricular performance is attributable primarily to increased volume load. In this respect supine exercise is probably superior to other forms of exercise in disclosing impaired left ventricular performance.

* The First Department of Internal Medicine, School of Medicine, Kanazawa University, Kanazawa, Japan.

** Cardiovascular Division, University of Iowa, Iowa City, Iowa.

This paper was presented at the Symposium "Hemodynamics" at the 36th Annual Meeting of the Japanese Circulation Society at Kanazawa on April 10, 1972.

Mailing address: Tsuneaki Sugimoto, M.D., First Department of Internal Medicine, School of Medicine, Kanazawa University, Takara-Machi 13-1, Kanazawa, Japan.

Received for publication September 9, 1974. 


\section{Additional Indexing Words:}

Ejection time Pre-ejection period Supine exercise Ventricular performance Heart failure

$7 \mathrm{HERE}$ is recent growing interest in systolic time intervals (STI) as a simple, non-invasive means of assessment of left ventricular performance in man. ${ }^{1-7)}$ Alterations in STI at rest have been shown to correlate with changes in stroke volume, cardiac output, ${ }^{18)}$ left ventricular ejection fraction, ${ }^{91}$ as well as with direct parameters of left ventricular contractility. ${ }^{101}$ More recently changes in STI in response to quantitated exercise have been examined in cardiac patients ${ }^{11-15)}$ and compared with the normal response. However, these studies have yielded controversial results. Therefore more work is needed to define the place of exercise induced changes in STI in disclosing impaired left ventricular performance and the type of exercise that is most useful in this respect.

The present study was undertaken with the following objectives: 1) clinically, to compare the changes of STI induced by supine exercise in patients with and those without congestive heart failure; 2) experimentally, to investigate the effect of different hemodynamic variables and of myocardial impairment on STI; and 3) to attempt to interpret changes in STI at rest and after supine exercise in patients with congestive heart failure in the light of clinical and experimental observations.

\section{Materials and Methods}

\section{Clinical Study:}

The human subjects comprised 21 healthy adults (Group I) and 33 patients with heart disease. Cardiac patients consisted of 29 men and 4 women with an age range 16-65 years. Eighteen of these patients (Group II) had normal effort tolerance (N.Y. functional class I) and no prior history of heart failure; these included 13 patients with ischemic heart disease (IHD) with an old uncomplicated myocardial infarction or angina pectoris on severe exertion and 5 patients with primary myocardial disease (PMD) diagnosed by cardiomegaly with or without gallop rhythm but associated with ECG abnormalities exclusive of left bundle branch block. The remaining 15 patients (Group III) had a history of congestive heart failure (CHF) that was controlled satisfactorily by medical treatment so that their effort tolerance was ultimately only slightly decreased from normal (N.Y. functional class II). Twelve of these patients were suffering from ischemic heart disease and 3 had primary myocardial disease.

Patients included in the study were exercised by a Collins pedal mode bicycle ergometer* in the supine position for 4 min at a work load of 1 watt $/ \mathrm{Kg}$ of body

\footnotetext{
* Warren E. Collins, Inc.
} 
weight. Systolic time intervals, blood pressure, as well as cardiac output, were measured before and after exercise.

Systolic time intervals were obtained from simultaneous external recordings of carotid pulse, phonocardiogram and electrocardiographic Lead II by a Fukuda MRR-150 recorder at a paper speed of $100 \mathrm{~mm} / \mathrm{sec}$ with $10 \mathrm{msec}$ time lines. Carotid pulse was recorded using a Fukuda TY302 transducer. The phonocardiogram was obtained using a Fukuda TY301 microphone positioned in the left third intercostal space just outside the sternal border.

Left ventricular ejection time (ET) was measured from the onset of rapid carotid upstroke to the trough of the incisura in carotid pulse tracing. Q-2 interval was measured as the interval from the beginning of QRS complex to the first high frequency vibration of the aortic component of the second heart sound. Pre-ejection period (PEP) was calculated by subtracting ET from Q-2 interval. Measurement of these intervals was made to the nearest $5 \mathrm{msec}$ on the beat whose preceding $\mathrm{R}-\mathrm{R}$ was closest to the average R-R interval of 10 consecutive beats. Deviations from the normal for ET and PEP ( $\Delta \mathrm{ET}$ and $\Delta \mathrm{PEP}$ ) in milliseconds were calculated as the difference between the observed intervals and those predicted for normal individuals at the given heart rate according to the regression equations:

$$
\begin{aligned}
& \text { PEP }(\mathrm{msec})=-0.31 \times \text { heart rate }+122 \\
& \text { ET }(\mathrm{msec})=-1.4 \times \text { heart rate }+384
\end{aligned}
$$

These equations were derived from a previous study on 122 normal subjects. ${ }^{16}$ )

Cardiac outputs were measured by the dye dilution method using an earpicce photocell (Waters Co, Model RR-52).

\section{Experimental Study:}

The experimental study was performed on 8 mongrel dogs weighing 10 to $13 \mathrm{Kg}$. Animals were anesthetized with intravenous injection of sodium pentobarbital in a dose of $30-35 \mathrm{mg} / \mathrm{Kg}$ body weight and an additional dose was supplemented when necessary. Under artificial ventilation, the chest was opened at the left fourth intercostal space. The descending aorta was sectioned to introduce a blood circuit (Fig. 1) which consists of Starling's resistance, a blood reservoir, an adjustable pump, and an electromagnetic flowmeter probe. ${ }^{17}$ By this extracorporeal circuit, diastolic aortic blood pressure and cardiac output could be controlled independently at desired levels. For pressure measurement, a catheter was inserted into the ascending aorta via the right carotid artery and another was introduced directly into the left atrium via the left atrial appendage. Branches arising from the aortic arch were then ligated. Heart rate was controlled by electrical pacing with a bipolar electrode sutured on the right atrium. Flow rate through the distal descending aorta and the left common carotid artery (Fig. 1) was assumed to approximate the venous return to the left heart and was termed cardiac output.

Left atrial mean pressure, aortic pressure, electrocardiogram, and aortic mean flow rate were recorded at a paper speed of $200 \mathrm{~mm} / \mathrm{sec}$. Left ventricular ejection time (ET) was measured from the aortic pressure tracings as the interval from beginning of the fast upstroke to the dicrotic notch and pre-ejection period (PEP) was measured as the interval between the $Q$ wave of electrocardiogram and the onset of aortic pressure upstroke. Heart rate was calculated from $R-R$ intervals.

Measurements of ET and PEP were carried out while changing heart rate, 


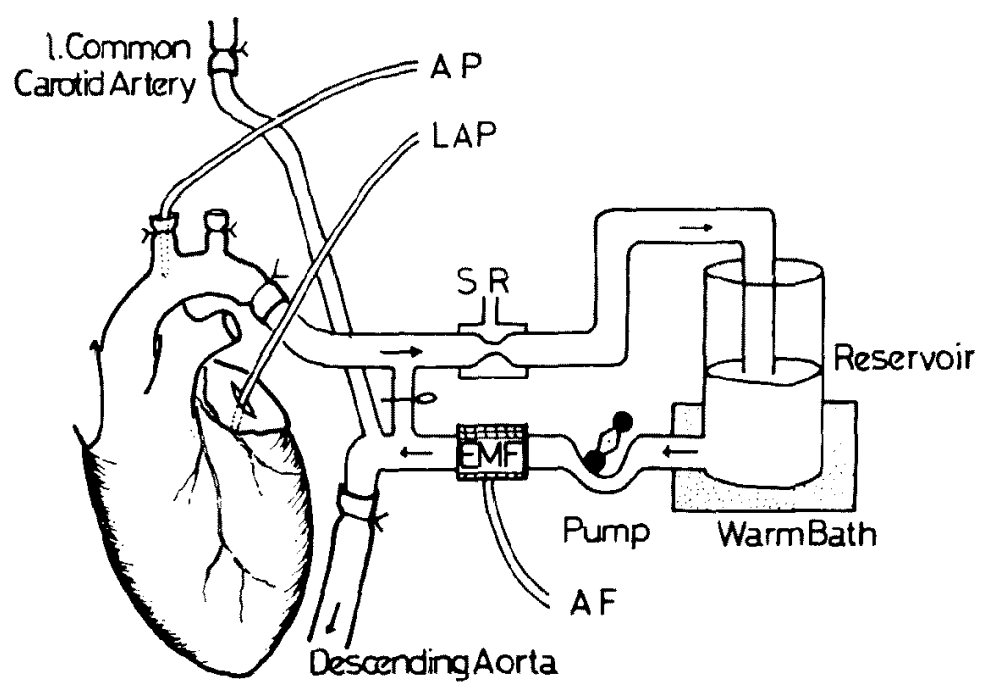

Fig. 1. Schematic representation of the perfusion system in the experimental study. SR=pneumatically controlled resistance of the Starling type; $\mathrm{EMF}=$ electromagnetic flow transducer; LAP =left atrial pressure; $A F=$ aortic flow through the perfusion pump.
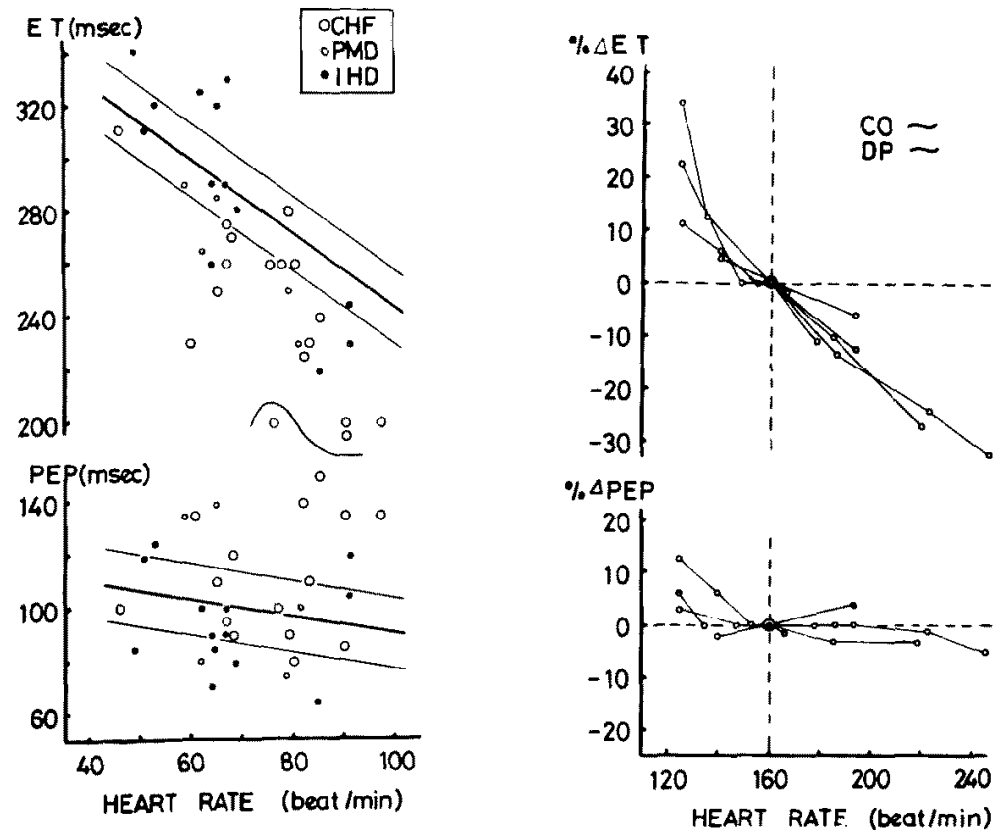

Fig. 2. Left panel shows left ventricular ejection time (ET) and preejection period (PEP) in Group II cardiac patients with ischemic (IHD) and primary myocardial disease (PMD), and Group III patients with congestive heart failure $(\mathrm{CHF})$. The regression lines represent normal values obtained from 122 healthy subjects. Right panel shows percentage change of PEP and $E T$ with changc in heart rate in animals with intact hearts while cardiac output (CO) and aortic diastolic pressure (DP) were kept constant. 
aortic diastolic pressure and cardiac output one at a time while the other variables were kept constant. Subsequently, myocardial depression was induced by adding $500-1,000 \mathrm{mg}$ of sodium pentobarbital to the blood reservoir perfusing the heart until elevation of mean left atrial pressure was observed. The experiment was then repeated after left atrial pressure had stabilized over $5 \mathrm{~min}$ at the new higher level.

\section{RESULTS}

I. Effect of Changes in Hemodynamic Variables on STI

A. Clinical Study: Heart rate and STI in cardiac patients were compared to the regression lines in normal controls obtained from a previous study. ${ }^{16)}$ As seen in Fig. 2, most patients with congestive heart failure in this study had longer PEP and shorter ET at rest. Prolongation of PEP and shortening of ET in these patients tended to be more pronounced in patients with lower resting cardiac index but was generally independent of diastolic arterial blood pressure (Fig. 3). Group II cardiac patients (IHD, PMD) had normal STI, with few exceptions, even when they had a relatively low cardiac index. PEP/ET ratio was $0.343 \pm 0.043$ in Group I (normal subjects), $0.336 \pm$ 0.079 in Group II (IHD), $0.403 \pm 0.078$ in Group II (PMD), and $0.489 \pm$
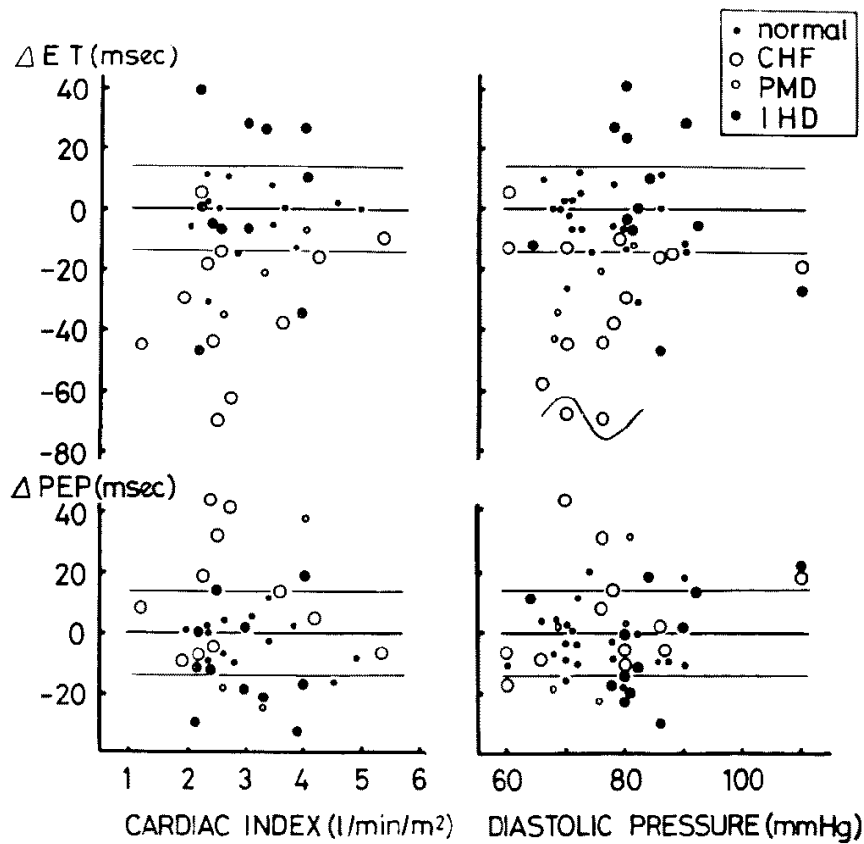

Fig. 3. Relationship between $\triangle \mathrm{PEP}$ and $\triangle \mathrm{ET}$ and cardiac index (left panel) and aortic diastolic pressure (right) in the different groups of patients, $\triangle \mathrm{PEP}$ and $A \mathrm{ET}$ are the deviations of those valucs from the mean values obtained from 122 normal subjects ( 0 lines). 


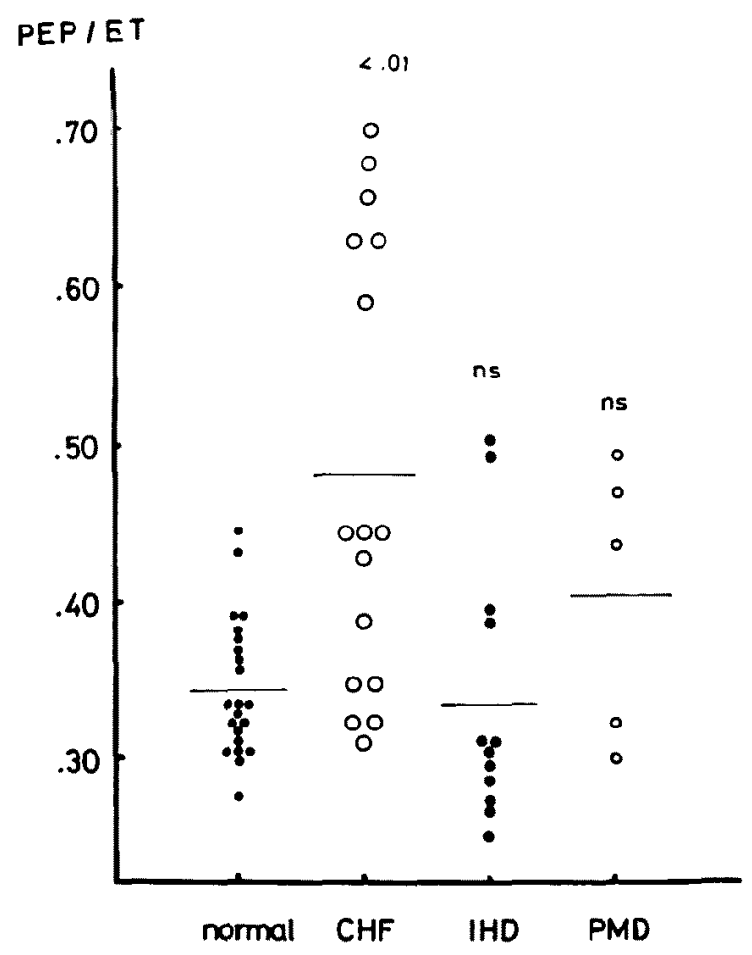

Fig. 4. The distribution and mean values (transverse lines) of PEP/ET in the different groups of patients. Patients with congestive heart failure (CHF) had significantly higher PEP/ET than normal $(p<0.01)$. Group II patients (IHD, PMD) had values that are not significantly (ns) different from normal.

0.078 in Group III (CHF pts.), thus indicating a significantly higher value in this latter group $(\mathrm{p}<0.01)$ (Fig. 4).

B. Experimental Study: The effects of change in each of heart rate, aortic diastolic pressure and minute cardiac output on STI were studied experimentally in dogs. As heart rate was increased at a constant stroke volume and aortic diastolic pressure, there was shortening of PEP accompanied by more pronounced shortening of ET (Fig. 5A). Increase in heart rate with a constant minute cardiac output, i.e., at a lower stroke volume, caused less marked shortening of PEP and more marked shortening of ET than when stroke volume was kept constant (Fig. 2). Increase of stroke volume at a constant heart rate and arterial diastolic pressure resulted in prolongation of ET and simultaneous shortening of PEP (Fig. 5B). Elevation of aortic diastolic pressure at a constant heart rate and stroke volume resulted in prolongation of PEP and shortening of ET. This change was observed until a pressure of about $100 \mathrm{mmHg}$, beyond which further increase of aortic diastolic pressure 


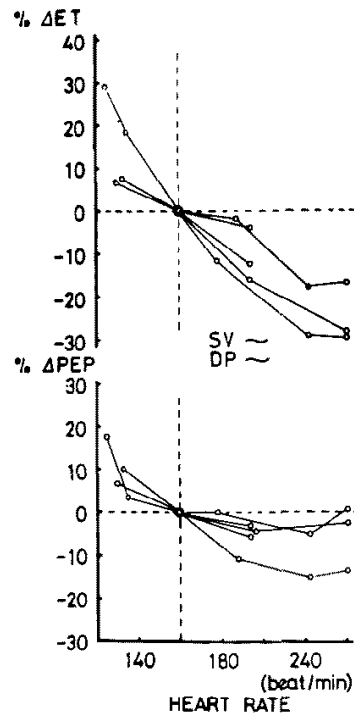

A

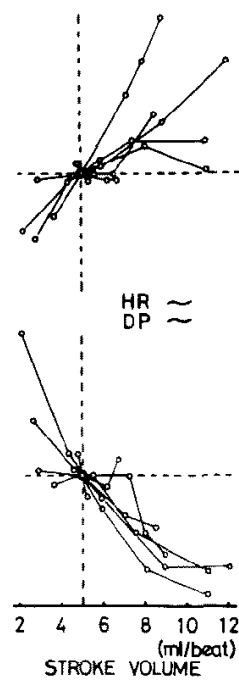

B

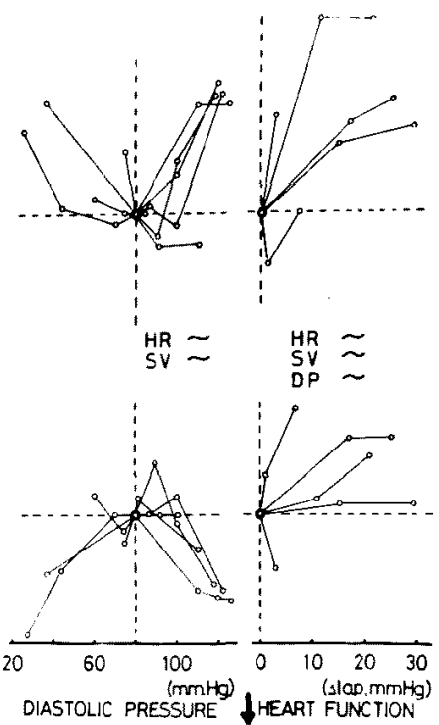

C

D

Fig. $5 \mathrm{~A}, \mathrm{~B}, \mathrm{C}$ and D. Experimental study: Effect of change of each of heart rate (HR), stroke volume (SV), arterial diastolic blood pressure (DP), and induced impairment of myocardial function on PEP and ET while other hemodynamic variables are kept constant $(\sim) . \% \Delta \mathrm{PEP}$ and $\% \Delta \mathrm{ET}=$ percentage change in these intervals from control values. Slap $=$ increase in left atrial pressure above control values with induced impairment of myocardial function.

resulted in abbreviation of PEP and prolongation of ET (Fig. 5C). When myocardial depression was induced by a large dose of sodium pentobarbital, while the other hemodynamic variables were kept the same as with the intact heart, there was prolongation of both ET and PEP (Fig. 5D) with increase in PEP/ET.

II. STI Changes Induced by Excrcisc or Incrcased Stroke Volume

A. Clinical Study: Table I shows hemodynamic changes induced by supine exercise in the different groups studied. Normal individuals (Group I) showed increase in heart rate and cardiac index, but insignificant change in stroke volume and arterial diastolic blood pressure (Table I). Fig. 6 shows exercise-induced changes in STI in the studied groups. There was prolongation of ET and shortening of PEP in Groups I and II while there was prolongation of both PEP and ET in Group III. Postexercise PEP/ET showed a further significant increase in Group III $(p<0.01)$ while the ratio decreased in Groups I and II (Fig. 7).

B. Experimental Study: In dogs, changes in STI were studied in re- 
Table I. Hemodynamic Changes Induced by Supine Exercise in the Different Groups Studied

\begin{tabular}{|c|c|c|}
\hline & At rest & After exercise \\
\hline \multicolumn{3}{|c|}{ Cardiac index $\left(\mathrm{L} / \mathrm{min} / \mathrm{M}^{2}\right)$} \\
\hline Group I & $3.0 \pm 0.9$ & $4.6 \pm 1.6$ \\
\hline Group II-IHD & $3.0 \pm 0.7$ & $4.7 \pm 1.8$ \\
\hline$-\mathrm{PMD}$ & $3.2 \pm 0.7$ & $5.5 \pm 1.8$ \\
\hline Group III & $2.6 \pm 0.9$ & $3.1 \pm 0.7$ \\
\hline \multicolumn{3}{|c|}{ Stroke volume index $\left(\mathrm{ml} /\right.$ beat $\left./ \mathrm{M}^{2}\right)$} \\
\hline Group I & $43 \pm 10$ & $57 \pm 20$ \\
\hline Group II-IHD & $47 \pm 15$ & $62 \pm 30$ \\
\hline$-\mathrm{PMD}$ & $47 \pm 12$ & $60 \pm 11$ \\
\hline Group III & $36 \pm 10$ & $33 \pm 7$ \\
\hline \multicolumn{3}{|l|}{ Heart rate (beats/min) } \\
\hline Group I & $70 \pm 10$ & $85 \pm 11$ \\
\hline Group II-IHD & $68 \pm 13$ & $81 \pm 16$ \\
\hline PMD & $69 \pm 9$ & $92 \pm 15$ \\
\hline Group III & $71 \pm 12$ & $93 \pm 16$ \\
\hline \multicolumn{3}{|c|}{ Diastolic blood pressure $(\mathrm{mmHg})$} \\
\hline Group I & $75 \pm 8$ & $76 \pm 10$ \\
\hline Group II-IHD & $84 \pm 11$ & $94 \pm 10$ \\
\hline$-\mathrm{PMD}$ & $73 \pm 6$ & $69 \pm 13$ \\
\hline Group III & $80 \pm 13$ & $74 \pm 28$ \\
\hline
\end{tabular}

The values are mean \pm 1 standard deviation. Group $\mathrm{I}=$ normal individuals; Group $\mathrm{II}-\mathrm{IHD}=$ ischemic heart disease; Group II-PMD = primary myocardial disease; Group III=patients with prior congestive heart failure.
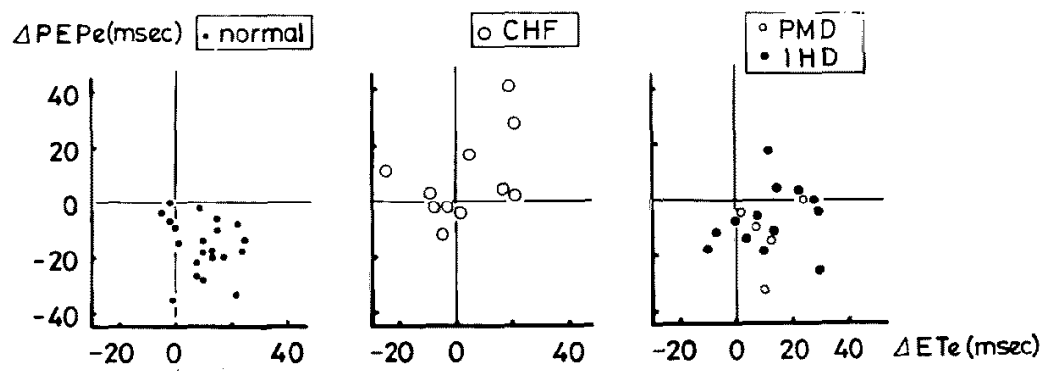

Fig. 6. Changes in PEP and ET from base line values in response to supine exercise $\left(\Delta \mathrm{PEP}_{\mathrm{Q}}\right.$ and $\Delta \mathrm{ET}_{\mathrm{e}}$ ) in Group I normal subjects, Group III congestive heart failure patients and Group II cardiac patients (IHD and PMD).

sponse to doubling of stroke volume while heart rate and arterial diastolic pressure were kept constant. As shown in Fig. 8, increase in stroke volume resulted in shortening of PEP and prolongation of ET while the heart was intact, but when myocardial depression was induced by pentobarbital, similar 


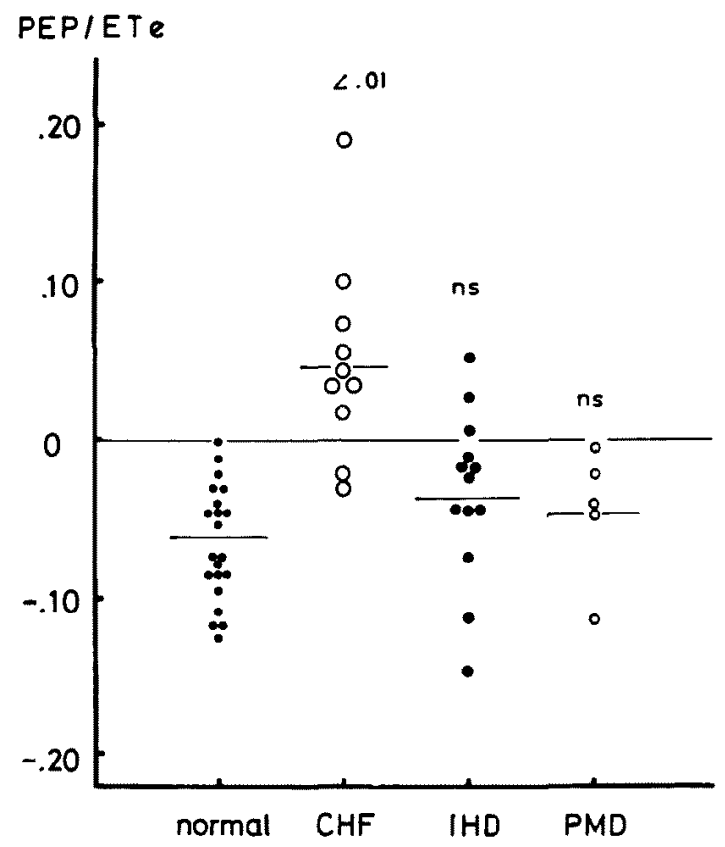

Fig. 7. Changes in PEP/ET from base line control values (0 line) in response to supine exercise (PEP/ETe) in the different groups of patients. Note the significantly higher values $(p<0.01)$ in CHF patients.

$\% \triangle P E P \quad$ intact heart

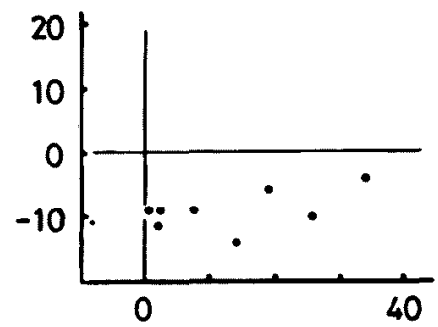

failing heart

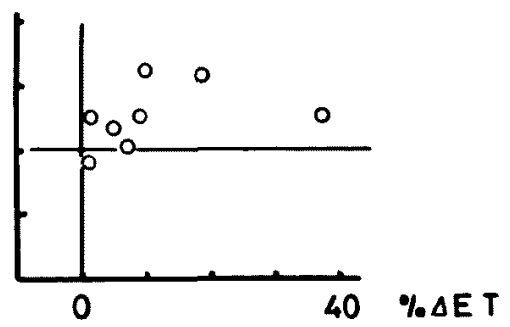

Fig. 8. Experimental study: Percentage change in PEP and ET from control values ( 0 line) in response to doubling of stroke volume while heart rate and diastolic blood pressure were kept constant. Left panel shows values with intact heart and right panel shows values after induction of myocardial impairment.

increase in stroke volume resulted in prolongation of both PEP and ET with increase in PEP/ET. The response of STI to increased preload in animals with intact heart is therefore similar to STI response to supine exercise in human subjects with healthy hearts or non-limiting heart disease. Also, STI response to increased volume load after induction of myocardial impairment 
in animals is similar to STI changes in response to supine exercise in patients with prior congestive heart failure.

\section{Discussion}

The present study conforms with previous reports showing that with intact hearts, while other hemodynamic variables are kept constant, increase in heart rate leads to shortening of PEP and marked shortening of ET while increase in venous return leads to shortening of PEP and prolongation of ET. ${ }^{18)-21)}$

Our data indicate that STI response to controlled elevation of diastolic blood pressure depends on the degree of such elevation; less severe elevation of blood pressure leads to prolongation of PEP and shortening of ET while further blood pressure elevation leads to reversal of these findings. Wallace et $\mathrm{al}^{21)}$ reported prolongation of PEP and shortening of ET in response to sudden increase of mean aortic pressure in animal experiments. Although there is no mention by these authors of a second phase in which STI values were reversed, close examination of their data suggests that with mean aortic pressures in excess of $120 \mathrm{mmHg}$ there was no further change of ET while total systole shortened in duration indicating PEP shortening. Furthermore, Mitchell et $\mathrm{al}^{22}$ ) have shown, in a similar experiment, that increase of mean aortic pressure from $58 \pm 2$ to $120 \pm 4 \mathrm{mmHg}$ did not alter myocardial contractility but further increase of pressure from $114 \pm 8$ to $139 \pm 8 \mathrm{mmHg}$ was accompanied by increased velocity of left ventricular fiber shortening and prolongation of ET. On the other hand, human experiments did not show an initial phase of PEP prolongation and ET shortening in response to methoxamine induced increase in mean aortic pressure; ${ }^{23)}$ the discrepancy may be due to the more gradual increase in aortic pressure in the latter experiments and/or an earlier enhancement of left ventricular contractility in human hearts.

In patients with heart disease deviation of STI from normal is probably primarily influenced by the degree of impairment of left ventricular performance. Our group of patients with ischemic heart disease or primary myocardial disease but no history of congestive failure not only had normal STI at rest but also behaved in response to supine exercise similarly to healthy individuals. By contrast, patients with the same type of underlying heart disease and limited effort tolerance had significantly different findings in STI at rest and in response to supine exercise.

The effect of exercise on cardiac performance probably consists of 2 major components; augmented sympathetic activity and increased venous 
return. ${ }^{24)}$ In the normal heart, increased sympathetic activity should lead to decrease in all components of mechanical systole ${ }^{25)}$ while increased venous return is expected to lead to shortening of PEP and prologation of ET. This latter pattern was encountered in healthy individuals and cardiac patients with normal effort tolerance whom we studied with supine excrcise. The primary role of increased venous return in causing these changes is further suggested from our experimental study in which controlled increase in stroke volume had similar effects on STI in animals with intact hearts. On the other hand, patients with prior congestive cardiac failure showed more prolongation of PEP and slight prolongation of ET and therefore appreciable increase in PEP/ET in response to supine exercise which is similar to our findings in animals with induced myocardial impairment when they were subjected to a larger volume load (Fig. 8).

Several investigators have studied exercise-induced changes in STI in symptomatic cardiac patients or those with subclinical or non-limiting heart disease. McConahay et $\mathrm{al}^{15}$ reported that patients with angina pectoris had significantly increased PEP and decreased ET and a greater PEP/ET at rest and after exercise than a control group of normal individuals. They also noted that cardiac patients showed an STI response to exercise similar to normal subjects. They therefore concluded that exercise did not improve the predictability of STI in differentiating patients with coronary artery disease from clinically healthy individuals. That study, however, did not include cardiac patients with prior congestive heart failure. Aronow et al ${ }^{13}$ showed that among patients with coronary heart disease, those with a left ventricular ejection fraction of less than $50 \%$ had a lesser decrease of isovolumic contraction time/ET in response to upright exercise than normal individuals or patients with an ejection fraction of $50 \%$ or more. These findings conform with those of Kondo ${ }^{11}$ who noted that exercise caused less than usual abbreviation of PEP in the majority of patients with heart disease. By contrast, Pouget et ald $^{12)}$ observed that 2 step exercise test for 4 min resulted in more prolongation of ET and more shortening of PEP than usual in patients with angina pectoris as well as in patients with heart failure due to primary myocardial disease.

The discrepancy in these results is not readily explainable, but the type of exercise employed might have influenced the results in certain studies. It has been shown that a normal individual in the supine position has a shorter PEP and a longer ET than values obtained in the upright position, while a patient with congestive heart failure will demonstrate no significant change in STI with posture. ${ }^{26)}$ Also stroke volume and cardiac output have been shown to be significantly lower during upright than supine exercise in normal subjects, whereas no significant difference in cardiac output or stroke volume was found 
in patients with heart disease with the 2 forms of exercise. ${ }^{27}$ If one considers that venous return increases appreciably in the supine position, one may expect that exaggerated cardiac distension in that position should make supine exercise more useful than urpight exercise in revealing an underlying state of impaired myocardial performance.

\section{ACKNOWLEDGMENT}

Our appreciation to Mrs. Hiroko Nishio and Julianne Garvey for their secretarial assistance.

\section{REFERENCES}

1. Weissler AM, Peller RG, Roehill WH, Jr: Relationship between left ventricular ejection time, stroke volume, and heart rate in normal individuals and patients with cardiovascular disease. Am Heart J 62: 367, 1971

2. Perry JR, Jr, Garrard CL: Systolic time intervals. Relation to severity of coronary artery disease and left ventricular dysfunction (Abst). Circulation 42 (Suppl. III): III-121, 1970

3. Hoges, Halpern BL, Friesinger GC, Dagenais GR: Left ventricular pre-ejection period and ejection time in patients with acute myocardial infarction. Circulation 45: 933, 1972

4. Lewis RP, Boudoulas H, Forester WF, Weissler AM: Shortening of electromechanical systole as a manifestation of excessive adrenergic stimulation in acute myocardial infarction. Circulation 46: 856, 1972

5. Weissler AM, Harris WS, Shoenfeld CF: Systolic time intervals in heart failure in man. Girculation 37: 149, 1968

6. Benchimol A, Diamond EG, Shen Y: Ejection time in aortic stenosis and mitral stenosis. Comparison between the direct and indirect arterial tracings, with special reference to pre- and post-operative findings. Am J Cardiol 5: 728, 1960

7. Moskowitz RL, Wechsler BM: Left ventricular ejection time in aortic and mitral valve disease. Am J Cardiol 15: 809, 1965

8. Weissler AM, Harris WS, Schoenfeld CD: Bedside techniques for the evaluation of ventricular function in man. Am J Cardiol 23: 577, 1969

9. Garrard CL, Jr, Weissler AM, Dodge HT: The relationship of alterations in systolic time intervals to ejection fraction in patients with cardiac disease. Circulation 42: 455, 1970

10. Ahmed SS, Levinson GE, Schwartz CJ, Ettinger PO: Systolic time intervals as measures of the contractile state of the left ventricular myocardium in man. Circulation 46:559, 1972

11. Kondo K: Evaluation of hemodynamics by exercise at a load of 1 watt $/ \mathrm{kg}$ of body weight. Chiba Med J 44: 4981968 (in Japanese)

12. Pouget JM, Harris WS, Mayron BR, Naughton JP: Abnormal responses of the systolic time intervals in exercise in patients with angina pectoris. Circulation 43: 289, 1971

13. Aronow WS, Bowyer AF, Kaplan MA: External isovolumic contraction times and left ventricular ejection time/external isovolumic contraction time ratios at rest and after exercise in coronary heart disease. Circulation 43:59, 1971

14. Pigott VM, Spodick DH, Rectra EH, Kahn AL: Cardiocirculatory responses to exercise. Physiologic study by noninvasive techniques. Am Heart J 82: 632, 1971

15. McConahay DR, Martin CM, Cheitlin MD: Resting and exercise systolic time intervals. Correlations with ventricular performance in patients with coronary artery disease. Circulation 45: 592, 1972

16. Inasaka T, Sugimoto T, Nohara T, Hirasawa K, Kaseno K, Uraoka T, Kitagawa S, Sato K, 
Takeuchi J: Usefulness of left ventricular systolic time intervals in the evaluation of cardiac performance. Shinzo 5: 21, 1972 (in Japanese)

17. Nohara T, Sugimoto T, Hirasawa K, Ohya N, Inasaka T, Kaseno K, Takeuchi J: Acute effects of low aortic pressure on cardiac performance. Pflügers Arch 331: 103, 1972

18. Wiggers CJ: Studies of the consecutive phases of the cardiac cycle. 2. The laws governing the relative durations of ventricular systole and diastole. Am J Physiol 56: 439, 1921

19. Blumberger KK, Meiners S: Studies of cardiac dynamics. In Cardiology Vol 2, 4-372, ed by Luisada AA, McGraw Hill, New York, 1959

20. Braunwald E, Sarnoff, SJ, Stainsby WN: Determinants of duration and mean rate of ventricular ejection. Circulat Res 6: 319, 1958

21. Wallace AG, Mitchell JH, Skinner NS, Sarnoff SJ: Duration of the phases of left ventricular systole. Circulat Res 12: 611, 1963

22. Mitchell $\mathrm{JH}$, Wallace $\mathrm{AG}$, Skinner NS: Relation between end-diastolic pressure and mean rate of ejection of left ventricle. Am J Physiol 211: 83, 1966

23. Shaver JA, Kroetz FW, Leonard JJ, Paley HW: The effect of steady-state increases in systemic arterial pressure on the duration of left ventricular ejection time. J Clin Invest 39: 1051, 1960

24. Braunwald E, Sonnenblick EH, Ross J, Jr, Glick G, Epstein SE: An analysis of the cardiac responses to exercise. Circulat Res $20 \& 21$ (Suppl 1): 1-44, 1967

25. Talley RC, Meyer JF, McNay LL: Evaluation of the pre-ejection period as an estimate of myocardial contractility in dogs. Am J Cardiol 27:384, 1971

26. Stafford RW, Harris WS, Weissler AM: Left ventricular systolic time intervals as indices of postural circulatory stress in man. Circulation 41: 485, 1970

27. Epstein SE, Beiser GD, Stampfer M, Braunwald E: Exercise in patients with heart disease. Effects of body position and type and intensity of exercise. Am J Cardiol 23: 572, 1969 